\title{
Identidades de gênero nos estudos de recepção de telenovela: um olhar sobre a produção stricto sensu da última década ${ }^{1}$
}

\section{Gender identities in recepcion studies of brazilian telenovela: an observation about the stricto sensu production in the last decade}

\section{Lourdes Ana Pereira Silva}

Doutora em Comunicação e Informação pelo PPGCOM/UFRGS. Professora do Mestrado Interdisciplinar em Ciências Humanas da Universidade de Santo Amaro e dos cursos de Jornalismo e Publicidade e Propaganda da mesma IES.

<lourde_silva@hotmail.com>

\section{Valquíria Michela John}

Doutora em Comunicação e Informação pelo PPGCOM/UFRGS. Professora do curso de Jornalismo da Universidade do Vale do Itajaí - Univali. Pesquisadora do grupo Monitor de Mídia.

$<$ michela@gmail.com>

\section{RESUMO}

Este artigo discute o panorama das pesquisas de recepção tendo como materiais de análise as teses e dissertações desenvolvidas nos Programas de Pós-Graduação em Comunicação na última década, aproveitando o corpus já estudado por Jacks e outros (2014). Analisou-se especificamente os estudos de recepção da telenovela desenvolvidos a partir da perspectiva das relações e identidades de gênero, aspecto pouco enfatizado nas pesquisas desenvolvidas na última década sobre a mais importante narrativa de ficção seriada brasileira. De um universo de 209 pesquisas analisadas, 24 se dedicaram à recepção da telenovela, das quais apenas quatro sob a perspectiva de gênero, embora as mulheres sigam sendo as informantes mais enfocadas na problematização da recepção desse conteúdo.

\begin{abstract}
This paper discusses the reception researches panorama having analyzed the thesis and dissertations developed in the Communication Post Graduation Programs in the last decade, taking the corpus already studied by Jacks et al (2014). We analyzed specifically the studies of brazilian telenovela recepction developed from the gender relations and gender identities perspective. Aspect with little emphasis on researches developed on the last decade about the most important Brazilian serial fiction narrative. From the 209 researches analyzed, 24 were dedicated to reception of brazilian telenovelas, in which only four were about the gender perspective, even though women continue being the most focused informants of the problematization in these content reception studies.
\end{abstract}

Keywords: Reception studies. Brazilian telenovela. Gender.

1 Este artigo contou com a colaboração do Mestrando em Jornalismo pela UFSC, Felipe da Costa, o qual atuou na coleta e análise dos dados da pesquisa que resultou no capítulo do livro citado ao longo deste artigo. 


\section{Introdução}

É fundamental, para o desenvolvimento de qualquer pesquisa, conhecer o que já foi produzido sobre seu objeto. Essa conduta possibilita estabelecer o diálogo com outros estudos que se debruçam sobre o mesmo objeto, tema ou, ao menos, sobre o mesmo cenário. Apesar da importância desse mapeamento, como reforçam Jacks, Menezes e Piedras (2008), nem sempre essa prática é contemplada nos estudos realizados na área da Comunicação. Escosteguy (2008) enfatiza esse aspecto ao afirmar que:

Não temos o hábito de produzir 'estados da arte', ao contrário do que acontece em outros contextos geográficos e disciplinares. [...] a pesquisa feita no campo acadêmico da comunicação é com frequência invisível aos próprios pesquisadores em comunicação (Escosteguy, 2008, p. 9).

Muitas pesquisas desenvolvidas nos Programas de Pós-Graduação da Comunicação, apesar de lidarem com objetos, cenário empírico e/ou enfoque teórico metodológicos similares, quando não os mesmos, raras vezes estabelecem o diálogo entre si.

Mapear o que foi produzido na área é, então, uma forma de se colocar em diálogo, de estabelecer análises de continuidade, reforço ou contestação de resultados, processo salutar para o desenvolvimento do conhecimento. Naturalmente, não é possível mapear todas as análises realizadas, mas ao menos estabelecer um recorte que possibilite um panorama mínimo da área em que se atua e se desenvolve a pesquisa. Portanto, aqui se fez um recorte que enfatiza a produção na área específica da Comunicação, ciente de que isso deixa lacunas. Assim, o principal recorte para mapear o estado da questão aqui proposto foram as teses e dissertações desenvolvidas nos Programas de Pós-Graduação em Comunicação da última década aproveitando o corpus já estudado por Jacks e outros (2014).

O "estado da questão" aqui proposto refere-se, de modo ainda mais específico, às pesquisas de recepção de telenovela, particularmente, aquelas que estabeleceram análise e reflexões sob a perspectiva das relações de gênero, aspecto pouco enfatizado nos estudos desenvolvidos na última década, como se verá a seguir.

\section{Procedimentos adotados para a análise}

A abordagem metodológica deste trabalho consiste na realização do estado da arte, ou seja, mapear e discutir os estudos de recepção em telenovela 
que trabalham com identidade de gênero. O recorte do campo de conhecimento feito é o da comunicação stricto sensu, na última década, especificamente as teses e dissertações produzidas no intervalo de 2000 a 2009, aproveitando o corpus mapeado e discutido por Jacks e outros (2014). Segundo Jacks e outros (2014), no período de 2000 a 2009, foram desenvolvidas 5.715 pesquisas nos atuais 44 Programas de Pós-Graduação em Comunicação brasileiros. Desses, 4.249 se deram no âmbito do mestrado e 1.466 , no doutorado. Desse conjunto de trabalhos, "[...] somente 209 tratam dos processos e práticas de recepção dos meios de comunicação de forma empírica, os chamados estudos de recepção". Os conteúdos mais estudados foram o jornalismo, com 54 pesquisas, e a telenovela, eleita em 24 dos 209 estudos de recepção desenvolvidos.

Esta análise é, portanto, um novo olhar a partir do material discutido pelos autores na referida obra, da qual participaram os autores deste artigo. Os procedimentos metodológicos adotados, tanto para a produção do livro que deu base documental quanto para esta análise específica, consistiram basicamente em três etapas:

A $1^{\text {a }}$ etapa diz respeito ao mapeamento dos trabalhos. ${ }^{2}$ Esta etapa do processo da pesquisa evidencia o reconhecimento do aspecto cumulativo do conhecimento científico produzido. Neste artigo, o corpus ${ }^{3}$ compreendeu especificamente os estudos de recepção da telenovela desenvolvidos no intervalo de 2000 a 2009 a partir da perspectiva das relações e identidades de gênero, estabelecendo, portanto, o diálogo entre as 24 pesquisas sobre telenovela conforme analisado por Silva (2014) e as 30 sobre mulheres e/ou relações de gênero, seguindo a análise feita por John e Costa (2014). A ênfase maior da discussão recai, porém, sobre as 24 pesquisas de recepção que enfocaram a telenovela. Destas, 15 são dissertações e nove são teses. A produção dessas teses se deu nos seguintes estados brasileiros: São Paulo (16), Rio Grande do Sul (4), Minas Gerais (2), Rio de Janeiro (1) e Distrito Federal (1).

A $2^{\text {a }}$ etapa consiste na leitura integral das teses e dissertações e no fichamento das mesmas; os trabalhos são classificados a partir de abordagens. Neste artigo optou-se por trabalhar somente com a abordagem sociocultural, entendida "como o modo de tratar o objeto, a visão do pesquisador sobre o

2 O Banco de Teses da Coordenação de Aperfeiçoamento de Pessoal de Nível Superior (CAPES) e, em alguns casos os bancos de teses e dissertações das universidades, constituem-se nas principais fontes documentais desta pesquisa.

3 Cabe ressaltar que, do universo de 209 já estudados por Jacks e outros (2014), elegemos o corpus de 24 trabalhos, conforme já descrito. 
assunto, isto é, seu ponto de vista teórico e a maneira ou método de enfocar, ou de interpretar o fenômeno" (Escosteguy, 2004, p.135).

A $3^{a}$ etapa refere-se à produção da pesquisa em si, visando a realização de um panorama que possibilite contribuir com a sistematização e análise da temática, evidenciando avanços e lacunas sobretudo no que diz respeito aos aspectos teóricos metodológicos da pesquisa. Os resultados são discutidos a seguir, primeiramente uma apresentação geral dos estudos de telenovela, depois dos estudos de gênero e, em seguida, a ênfase nos estudos de telenovela sob a perspectiva de gênero.

\section{Telenovela e identidade, entrelaçamentos possíveis}

Um dos aspectos importantes a destacar no panorama das pesquisas sobre recepção de telenovela é o processo histórico que caracterizou a trajetória desse objeto de pesquisa nos estudos de recepção no campo da comunicação. Mais de meio século de veiculação de telenovela no Brasil a transformou em um fenômeno de grande impacto no cotidiano de milhares de pessoas e a legitimou como um ícone da cultura de massa e como um dos produtos de maior consumo da televisão brasileira.

No contexto da década analisada, a de 2000, a telenovela ultrapassa a função de mero entretenimento devido às inúmeras transformações pelas quais passam a esfera da produção e da recepção, reconfigurando desse modo a teledramaturgia nacional. Na ótica da produção, as mudanças vão desde a inclusão veloz de novas tecnologias e da concorrência aguerrida entre emissoras até o alto nível artístico e estético das narrativas. Quanto à recepção, pode-se ressaltar as transformações caracterizadas pelos modos diversificados de assistir à telenovela - devido, sobretudo, ao maior acesso à internet - e pela exigência das audiências de querer sempre mais verossimilhança entre ficção e realidade social - consequência de uma competência técnica dos telespectadores, acumulada ao longo de mais de seis décadas de convivência com esse produto.

Apesar disso, não se pode esquecer que, durante um bom tempo, a telenovela permaneceu à margem da academia e só começou a despertar seu interesse, enquanto objeto de estudo, a partir dos anos 1980, consequência da hegemonia frankfurtiana que caracterizou a pesquisa midiática brasileira nas décadas de 1960 e 1970. Assim, o tema só despertou o interesse acadêmico na década posterior, coincidindo de algum modo com o esgotamento do regime militar e com a atenção que a mídia começou a dar ao fenômeno. Nesse cenário, as pesquisas realizadas foram de cunho histórico sobre o gênero de ficção televisiva, a exemplo do inventário da memória da telenovela brasileira, feito por 
Ismael Fernandes em 1982, e da análise da evolução do formato telenovelesco, organizada por Renato Ortiz e equipe em 1988 (Marques de Melo, 2004).

Além desses aspectos históricos permitirem identificar as condições sociais de produção do conhecimento sobre esse objeto de estudo, possibilitam também afirmar que a identidade é a temática mais recorrente na última década quando se trata dos estudos de recepção na área da comunicação. Essas iniciativas têm agrupado um conjunto de trabalhos que refletem sobre os estudos de recepção de telenovela a partir de distintos aspectos e enfoques, e que possibilitam assegurar, que apesar de a telenovela ter sido considerada tardiamente como objeto de estudo na academia, a trajetória feita dos anos 1980 até os dias atuais demonstram que se trata de um objeto de estudo consolidado.

Considerando o corpus, as pesquisas que trabalharam na perspectiva da abordagem sociocultural, tiveram por objetivo estudar a identidade enquanto fenômeno, verificando seus processos de constituição, como mediação constitutiva da interação entre audiência e televisão/telenovela. O que significa dizer que tais pesquisas situaram essas narrativas para além dos sentidos das mensagens, isto é, se preocuparam com o que transborda delas e, desse modo, ampliaram a inter-relação entre comunicação e cultura, posicionando a problemática do estudo de telenovela na complexidade do discurso social mais amplo e não restringindo ao discurso ideológico. Desse modo, os trabalhos que abordaram essa temática expressam heterogeneidade nas denominações identitárias e evidenciam que os processos culturais se encontram vinculados às relações sociais. Verificou-se que a temática das identidades foi estudada em suas mais variadas especificidades: étnicas (afro, indígena, europeia), rural, regional, cultural, familiar, racial, de gênero (feminino) e de orientação sexual.

Além da temática da identidade, esses trabalhos de recepção de telenovela se dedicaram a estudar a produção de sentidos, memória, relações de gênero, consumo, comportamento, merchandising e experiência cultural. A multiplicidade de recortes feitos nesses trabalhos demonstra como um objeto pode se reconfigurar continuamente, dada a dinamicidade dos contextos e problemáticas que o mobilizam, dinamizam e o subvertem, com sua natureza necessariamente histórica. Outro aspecto que cabe ressaltar, trata-se dos teóricos mais utilizados, repetem o que foi registrado na década anterior ${ }^{4}$ : Jesús Martín-Barbero, seguido por Nestor García Canclini, Guillermo Orozco Gómez e Stuart Hall. Observa-se, desse modo, que os estudos de recepção de telenovela

4 Ver Jacks, Menezes e Piedras (2008). 
fazem adesão, principalmente, ao pensamento de inspiração teórica latinoamericana, não chegando ainda a incorporar autores brasileiros.

Quanto aos aspectos teórico-metodológicos desses trabalhos, verifica-se ainda que estes nem sempre são explicitados, ou ao menos em que dimensão se deu o método, as técnicas e os procedimentos, todavia, pode-se perceber que em se tratando de modelo, o mais empregado é o das mediações, sendo Jesús Martín-Barbero a principal referência. Na maioria dos casos, tais pesquisas carecem de explicitação teórica conscientes da metodologia utilizada (Silva, 2014). Urge teorizar os métodos, técnicas e instrumentos de pesquisas, evidenciar os procedimentos analíticos e interpretativos, considerando que eles são fundamentais para construir o objeto e contribuir para a resolução do problema. Com isso, algumas vezes fica evidente que, quando os autores não têm clareza do objeto de pesquisa, consequentemente isto se reflete na metodologia, resultando a descrição lógica e cronológica do método, a exemplo de amostras mal construídas ou mal explicitadas nos relatos de pesquisa; dos procedimentos e técnicas não problematizados à luz do objeto e do problema de pesquisa. Essa lacuna se torna evidente também na estrutura geral da produção de algumas pesquisas e na ausência de referências específicas sobre metodologia.

\section{Estudos de recepção pela perspectiva de gênero: considerações gerais}

John e Costa (2014) mapearam, entre os 209 trabalhos que integram o corpus da pesquisa realizada por Jacks e outros (2014), $30^{5}$ deles com ênfase em mulheres e/ou na questão das relações de gênero. Ou autores ressalvam que a expressão "ou" se deve ao fato de que nem sempre houve essa correlação. "Há pesquisas que adotaram mulheres como sujeitos do estudo, sem, no entanto, passar pela questão de gênero e há trabalhos que abordaram essa temática a partir de homens (2) ou de homens e mulheres (4)". No que se refere aos procedimentos para mapear esses trabalhos "[...] o objetivo inicial eram as pesquisas com as mulheres, mas, também, os trabalhos que abordavam a temática da identidade de gênero, daí a presença do público masculino" (John; Costa, 2014, p. 218). Do total de estudos que focaram exclusivamente em mulheres (24), pode-se dizer que $15^{6}$ deles discutiram a recepção sob a ótica das

5 Vale destacar que dos 30 estudos aqui analisados, apenas quatro foram desenvolvidos por pesquisadores homens, evidenciando que a preocupação com a identidade de gênero continua sendo majoritariamente das mulheres (John e Costa, 2014).

6 Vale a ressalva que esses trabalhos não necessariamente abordaram a problemática das relações de gênero e sim estabeleceram uma breve reflexão sobre isso. 
relações de gênero. Houve, assim, um crescimento em relação à década de 1990 quando foram realizados apenas sete trabalhos seguindo essa perspectiva ${ }^{7}$. É importante destacar, entretanto, que o número de pesquisas desenvolvidas nos programas de Pós-Graduação em Comunicação também foi significativamente maior, o que mostra um crescimento relativo. Dessas 15 pesquisas, apenas uma foi desenvolvida no âmbito do doutorado, 13 são socioculturais.

A recepção por parte das mulheres tem como foco os conteúdos televisivos, de revista, rádio e um estudo que relaciona TV e jornal. Portanto, nenhum estudo de recepção sob a perspectiva das identidades de gênero teve como foco a internet. É importante destacar a prevalência do conteúdo televisivo na recepção feminina sob a ótica de gênero, 11 no total. Contudo, se levarmos em conta que, no intervalo analisado foram realizados 111 estudos de recepção com ênfase nesse meio (Jacks e outros, 2014), esse número acaba por ser ainda bastante tímido.

O gênero televisivo mais estudado sob essa perspectiva foi a telenovela. Se levarmos em conta, porém, que dos 24 estudos de recepção que se dedicaram a esse gênero televisivo (Silva, 2014), apenas quatro o fizeram sob a ótica das relações de gênero, o número pode ser considerado baixo, notadamente por conta das várias referências a esse gênero ${ }^{8}$ como sendo algo da preferência das mulheres e que, possivelmente, poderia ser melhor compreendido e/ou problematizado ante a ótica dos papéis e identidades de gênero.

As pesquisas que destacaram a recepção feminina e discutiram as relações de gênero são provenientes, majoritariamente, do Rio Grande do Sul, com seis dos 15 estudos, seguido por São Paulo (três trabalhos) e Minas Gerais (dois), além de Bahia, Pernambuco, Distrito Federal e Goiás, com um trabalho cada.

Os autores mais referenciados nesses estudos não diferem do padrão encontrado no conjunto dos 24 estudos de recepção da telenovela já apontados, com a predominância dos teóricos latino-americanos Jesús Martin-Barbero, Néstor Garcia Canclini e Guillermo Orozco, bem como a presença significativa de Stuart Hall. Nas pesquisas sobre recepção e mulheres, Martin-Barbero e Stuart Hall foram os mais utilizados, presentes em sete trabalhos cada. Há também a presença de algumas pesquisadoras ligadas aos estudos sobre gênero. Autores brasileiros estão praticamente ausentes dessas discussões, sendo Ana Carolina

7 Para maior detalhamento da década de 1990, ver Jacks, Menezes e Piedras (2008).

8 Ressalta-se que o termo gênero aqui se refere ao conteúdo midiático. Embora a palavra seja recorrente ao longo deste capítulo em referência às identidades femininas e masculinas e seus atributos sociais e culturais, o termo, justamente por não ser específico, pode ter mais de uma acepção, como é o caso neste momento. 
Escosteguy, Silvia Borelli e Vera Veiga França as pesquisadoras mais citadas, em um trabalho cada9.

Parte desse cenário pode ser explicada pelo fato de os autores mais citados serem os mais diretamente ligados às escolhas teórico-metodológicas dos trabalhos. Há de se destacar, porém, a importância de se estabelecer um diálogo mais interdisciplinar entre os teóricos dos estudos de recepção e as autoras das pesquisas sobre gênero, sobretudo na discussão dos resultados. Embora autores dos estudos de gênero tenham sido utilizados, esses estão muitas vezes restritos a um capítulo teórico e/ou histórico sobre o tema, sem efetivamente estarem articulados à análise da recepção propriamente dita, o que leva a sua quase invisibilidade na lista dos mais citados. Outro possível motivo para a evidência dos autores mais citados pode estar ligado ao fato de a temática mais recorrente ter sido a questão da identidade.

\section{Recepção da telenovela sob a ótica de gênero}

Desses 15 estudos sobre identidades de gênero, como dito no tópico anterior, 11 deles têm a televisão como seu objeto de estudo. Especificamente sobre telenovela, foram quatro pesquisas ${ }^{10}$, dos quais três realizam a efetiva discussão sobre as identidades de gênero. São os estudos de Gonçalves (2002) ${ }^{11}$, Tonon (2005), Gomide (2006) e Sifuentes (2009).

Tonon (2005) e Gomide (2006) discutem a homossexualidade feminina a partir da recepção de telenovelas. A primeira discute a homossexualidade tendo como ponto de partida os dispositivos da sexualidade e as políticas das diferenças, fazendo um diálogo entre Michel Foucault (1926-1984) e Stuart Hall (1932-2014). Depois, apresenta a trajetória dos movimentos homossexuais, a homossexualidade feminina e sua representação na mídia. Discute, além da telenovela, outros gêneros como música. Gomide (2006) apresenta a história do movimento gay e lésbico, com ênfase nos estudos de gênero e a teoria queer nos Estados Unidos, e sua influência nos estudos brasileiros, para então discutir

9 Curiosamente, apesar de os estudos sobre mulheres serem desenvolvidos majoritariamente por mulheres (inclusive no corpus aqui analisado), elas figuram como minoria na lista de autores mais citados.

10 Outras três pesquisas estudaram o conteúdo jornalístico, além de Publicidade, Série Americana, Variedades e Talk Show, com um trabalho cada e uma pesquisa que não focalizou nenhum conteúdo em particular.

11 A divergência no número, antes citado três e aqui quatro deve-se ao fato de que o trabalho de Gonçalves não chega a efetivamente a realizar discussão sobre gênero, motivo pelo qual não foi destacada nesta apresentação dos estudos que articulam a problemática enfocada nesta pesquisa. 
a formação da identidade lésbica a partir da telenovela Senhora do Destino exibida pela Rede Globo em meados da década passada. Esses trabalhos evidenciam aprofundada discussão teórica sobre sexualidade e os papeis de gênero a ela relacionados, com destaque para a homossexualidade feminina.

São inovadores em relação ao panorama da década de 1990 ao abordarem uma temática que não havia sido tensionada pelos pesquisadores, possivelmente porque as próprias telenovelas raramente apresentavam esse tema em seus enredos. Esse aspecto foi ficando mais evidente ao longo dos anos 2000, com a temática da homossexualidade sendo explorada por seguidas narrativas, embora com mais destaque para a homossexualidade masculina. Tonon (2005) e Gomide (2006) articulam seus resultados empíricos às discussões sobre gênero, notadamente, às questões que envolvem a temática enfatizada os papeis e estereótipos relacionados ao exercício da sexualidade.

O terceiro estudo desenvolvido no período, a abordar a temática das identidades de gênero na recepção de telenovela foi o de Sifuentes (2009). A autora também explora a proposta das mediações de Martin-Barbero (2003) para a análise que realiza. Sifuentes (2009) problematiza a correlação entre as identidades de gênero e de classe como articuladoras de toda a pesquisa sobre a recepção de telenovela Caminhos das Índias ${ }^{12}$. 0 estudo, realizado com 12 mulheres de classes populares da cidade de Santa Maria/RS, teve como objetivo "[...] compreender como os embates e complementaridades entre a audiência da telenovela e os demais elementos do cotidiano - família, escola e classe social - conformam a identidade feminina de jovens mulheres de classe popular" (Sifuentes, 2009, p. 5). Há evidência de exaustivas leituras sobre gênero e busca frequente de relacionar esses escritos ao resultado de seu trabalho de campo, que evidencia, entre outros resultados, um processo de projeção dessas jovens mulheres às narrativas e personagens da telenovela. Ou seja, a identificação se dá, enfaticamente, a partir de um processo de correlação entre os enredos e sua vida cotidiana.

Além desses três estudos com ênfase na relação entre telenovela, mulheres e identidade de gênero, o corpus contempla ainda o estudo de Souza (2009), que não tem como foco específico a telenovela, mas que chega a discuti-la brevemente na perspectiva de um conteúdo midiático que trata da homossexualidade. O estudo tem como objetivo "[...] descrever a interpretação que alguns indivíduos da comunidade gay fazem a respeito de como a mídia de massa interpreta a mesma; e também como entendem a possibilidade da

12 Exibida pela Rede Globo no período de janeiro a setembro de 2009. 
existência de um segmento de mercado específico para eles" (Souza, 2009, p. 63). A identidade de gênero é o tema condutor da dissertação, entretanto a autora não o faz pela ótica das relações entre masculino e feminino, apesar de ter como entrevistados homens e mulheres. Souza (2009) fala sobre os papéis sociais de cada um para discutir a homossexualidade, mas não tem como foco o que diferencia gays e lésbicas, e sim suas visões sobre a sexualidade, consumo e a representação dos personagens homossexuais nas telenovelas. Na análise dos resultados, a autora discute o entendimento dos entrevistados sobre o que é ser homossexual, as dificuldades de aceitação e consumo.

Em relação à mídia, a autora afirma que "[...] o papel dos meios de comunicação é fornecer, entre outras coisas, subsídios para mudanças culturais [...]" (Souza, 2009, p. 81). Entretanto, a maioria dos entrevistados não se sente representada nas telenovelas. Segundo eles, há poucas personagens lésbicas e os gays são estereotipados e pouco diversificados, o que não contribui para a redução da homofobia. Apesar disso, outros entrevistados acreditam que ajuda a dar visibilidade ao tema.

Os estudos que têm uma reflexão mais completa são os de Tonon (2005) e Gomide (2006). O da primeira começa a discutir a homossexualidade a partir dos dispositivos da sexualidade e políticas das diferenças, fazendo um diálogo entre Foucault e Hall. Depois, apresenta a trajetória dos movimentos homossexuais, a homossexualidade feminina e sua representação na mídia. Aborda não só as telenovelas, mas também outros gêneros como música. Apesar do número restrito de trabalhos, ao contrário da maioria dos estudos discutidos por John e Costa (2014), os quatro trabalhos sobre recepção da telenovela sob a perspectiva de gênero discutem a temática de modo aprofundado e articulado à análise dos dados. $^{13}$

\section{Considerações finais}

Como dito, foram priorizadas as teses e dissertações produzidas no âmbito da Comunicação, mas tem-se ciência de que muitos outros estudos sobre este objeto podem ter sido realizados em outras áreas e que há pesquisas realizadas em outros âmbitos que não estão aqui contempladas. O que se buscou não foi esgotar o que já foi dito sobre recepção de telenovela e identidade de gênero, e sim tentar situar esta pesquisa no cenário da área em que ela é produzida.

13 De um modo geral, pode-se dizer que as discussões sobre sexualidade ocuparam e ocupam papel central nas reflexões feministas, motivo pelo qual, possivelmente, também os estudos de recepção que adentraram a esse universo o tenham feito com maior propriedade. 
Constata-se que conjugação entre os temas identidade de gênero e telenovela ainda é bastante restrita, com apenas quatro trabalhos que realizaram tal tensionamento, sendo a maioria deles a partir da perspectiva da sexualidade. Ainda que, como já dito, esse panorama seja restrito, evidencia-se um campo a ser explorado.

Destaca-se que, além dos quatro trabalhos aqui discutidos, outros entre os 24 que se dedicaram à recepção da telenovela adotaram o público feminino como sujeitos da pesquisa sem, contudo, estabelecer discussões relacionadas às identidades de gênero. Esse aspecto não constitui, a priori, uma problemática. Entende-se que uma vez explicitadas claramente as decisões metodológicas para a escolha dos informantes e não havendo o aparecimento dessa temática do campo de pesquisa, não há problema em trabalhar com mulheres sem que se faça discussões sobre sua identidade de gênero. Toda pesquisa, principalmente quando se trata da dissertação, dado seu curto período de execução, necessita de recortes e nem sempre é possível abordar todos os aspectos que dizem respeito à complexidade dos sujeitos participantes. Porém, faz-se necessário sempre realizar a explicitação teórico-metodológica sobre as escolhas quanto ao público receptor, o que nem sempre foi encontrado nos trabalhos que adotaram mulheres como informantes sem, no entanto, estabelecerem discussão sobre identidade de gênero.

De certo modo, nas pesquisas de recepção de telenovela sob a ótica das relações de gênero, aparentemente continua-se a trabalhar em um modelo binarista, tão criticado por outras disciplinas, notadamente a Antropologia. Aparentemente, continua-se a entender gênero como uma questão do "feminino", quando na verdade se trata da relação inter e intra sexos. A realização de pesquisas sobre identidade de gênero e telenovela a partir de receptores homens constitui-se ainda uma lacuna o que, de certo modo, reforça o estereótipo de que esse conteúdo é do interesse exclusivo das mulheres.

Sobre os estudos de recepção de telenovela de um modo geral, para além das questões relacionadas às identidades de gênero, considera-se que é de fundamental importância começar a considerar alguns aspectos, a exemplo da convergência midiática. A partir desse crescente fenômeno, é possível perceber que já não é suficiente estudar a recepção de telenovela somente a partir do meio televisão.

O estado da arte aqui realizado não se limita a conhecer o passado, mas em elucidar o presente buscando identificar as diferenças e as semelhanças dos trabalhos em questão, almejando instigar mudanças efetivas nas pesquisas que estão por vir. Desse modo, almeja-se que o estado da arte feito possa contribuir 
significativamente na constituição dos aportes teórico-metodológicos dos futuros estudos de recepção, uma vez que buscou-se identificar os avanços, desafios e lacunas daqueles que se propuseram a avançar nesta área do conhecimento.

\section{REFERÊNCIAS}

ESCOSTEGUY, Ana Carolina (Org). Comunicação e gênero: a aventura da pesquisa. Porto Alegre: EDIPUCRS, 2008.

Notas para um estado da arte sobre os estudos brasileiros de recepção nos anos 90. In: MACHADO, Juremir; LEMOS, André; SÁ, Simone Pereira de (Orgs.) Mídia. Br. Porto Alegre: Sulina, 2004.

JACKS, Nilda; MENEZES, Daiane; PIEDRAS, Elisa. Meios e audiências: a emergência dos estudos de recepção no Brasil. Porto Alegre: Sulina, 2008.

Meios e audiências II: a consolidação dos estudos de recepção no Brasil. Porto Alegre: Sulina, 2014.

JOHN, Valquiria Michela; COSTA, Felipe da. Mulheres, identidade de gênero e sexualidade: problemáticas e desafios a partir do recorte por sexo. In: JACKS, Nilda e outros. Meios e audiências II: a consolidação dos estudos de recepção no Brasil. Porto Alegre: Sulina, 2014.

MARQUES DE MELO, José. A esfinge midiática. São Paulo: Paulus, 2004.

SILVA, Lourdes Ana Pereira. Recepção de telenovela: a identidade em questão. In: JACKS, Nilda e outros. Meios e audiências II: a consolidação dos estudos de recepção no Brasil. Porto Alegre: Sulina, 2014.

\section{Teses e dissertações que serviram como base para a análise realizada}

BARBOSA, Luciene Cecília. Louca Paixão: Questões raciais na telenovela sob o olhar receptor. 2002. 164 f. Dissertação (Mestrado em Ciências da Comunicação) Escola de Comunicações e Artes, USP, São Paulo, 2002.

BARBOSA, Luciene Cecilia. As representações das relações raciais na telenovela brasileira - Brasil e Angola: Caminhos que se cruzam pelas narrativas da ficção. 2008. 192 f. Tese (Doutorado em Ciências da Comunicação) - Escola de Comunicações e Artes, USP, São Paulo, 2008.

BARROS JÚNIOR, Rui Coelho. Temáticas sociais em telenovelas e cultura popular cuiabana:Uma questão de negociação de sentidos. 2001.225 f.Tese (Doutorado em Ciências da Comunicação) - Escola de Comunicações e Artes, USP, São Paulo, 
2001.

BONIN, Jiani Adriana. Identidade étnica, cotidiano familiar e telenovela. 2001. 221

f. Tese (Doutorado em Ciências da Comunicação) - Escola de Comunicações e Artes, USP, São Paulo, 2001.

BUDAG, Fernanda Elouise. Comunicação, recepção e consumo: Suas inter-relações em Rebelde-RBD. 2008. 274 f. Dissertação (Mestrado em Comunicação e Práticas de Consumo) - Escola Superior de Propaganda e Marketing, ESPM, São Paulo, 2008.

FOGOLARI, Élide Maria. Fazenda Esperança: Estudo sobre as mediações culturais e a recepção da telenovela Terra Nostra. 2001. 297 f. Dissertação (Mestrado em Ciências da Comunicação) - Escola de Comunicações e Artes, USP, São Paulo, 2001.

GOMIDE, Sílvia Del Valle. Representações das identidades lésbicas na telenovela Senhora do Destino. 2006. 210 f. Dissertação (Mestrado em Comunicação) Faculdade Comunicação, UNB, Brasília, 2006.

GONÇALVES, Cláudia Siqueira Caetano. Laços televisivos, laços identitários, laços de família. 2002. 155 f. Dissertação (Mestrado em Comunicação) - Faculdade de Filosofia e Ciências Humanas, UFMG, Belo Horizonte, 2002.

HARTMANN, Attílio Ignácio. Religiosidade e mídia eletrônica: A mediação sociocultural, religiosa e a produção de sentido na recepção de televisão. 2000 . 352 f. Tese (Doutorado em Ciências da Comunicação) - Escola de Comunicações e Artes, USP, São Paulo, 2000.

LORETO, Maria Mariz. Televisão e nordestinos: Identidade regional e leitura diferenciada. 2003. 209 f. Dissertação (Mestrado em Comunicação) - Escola de Comunicação, UFRJ, Rio de Janeiro, 2003.

MARQUES, Jane Aparecida. Vozes da cidade: Os sentidos da telenovela na metrópole paulista. 2008. 235 f. Tese (Doutorado em Ciências da Comunicação) - Escola de Comunicações e Artes, USP, São Paulo, 2008.

MOGADOURO, Cláudia de Almeida. Do pátio à sala de aula: Possibilidades de discussão da telenovela. 2005. 183 f. Dissertação (Mestrado em Ciências da Comunicação) - Escola de Comunicações e Artes, USP, São Paulo, 2005.

OLIVEIRA, Maria Helena Castro de. Estrelas refletidas nas noites globais: Estudo de representações de idosos nas telenovelas da Rede Globo de Televisão. 2008. 324 f. Tese (Doutorado em Comunicação), Faculdade de Comunicação Social, PUC-RS, Porto Alegre, 2008. 
OLIVEIRA, Pedro Pinto. Terra Nostra: Recepção da telenovela em uma comunidade rural do Pantanal do Mato Grosso. 2000. 138 f. Dissertação (Mestrado em Ciências da Comunicação) - Escola de Comunicações e Artes, USP, São Paulo, 2000.

SIFUENTES, Lirian. Telenovela e mediações culturais na conformação da identidade feminina de jovens de classe popular. 2009. 245 f. Dissertação (Mestrado em Comunicação) - Faculdade de Comunicação Social, UFSM, Santa Maria, 2009.

SIMÕES, Paula Guimarães. Mulheres Apaixonadas e outras histórias: Amor, telenovela e vida social. 2004. 232 f. Dissertação (Mestrado em Comunicação) - Faculdade de Filosofia e Ciências Humanas, UFMG, Belo Horizonte, 2004.

SILVA, Lourdes Ana Pereira. Páginas da Vida, a família brasileira sob a ótica da recepção da telenovela. São Leopoldo: UNISINOS, 2008. 172 f. Dissertação (Mestrado em Ciências da Comunicação- Escola da Indústria Criativa, UNISINOS, São Leopoldo, 2008.

SOUZA, Joseleide Terto de. Contextos contemporâneos: Homossexuais, cultura e mídia. 2009. 160 f. Dissertação (Mestrado em Ciências da Comunicação) - Escola de Comunicações e Artes, USP, São Paulo, 2009.

STROHSCHOEN, Ana Maria. Mídia e memórias coletivas. 2003. 211 f. Tese (Doutorado em Ciências da Comunicação) - Escola da Indústria Criativa, UNISINOS, São Leopoldo, 2003.

TONIAZZO, Gladis. A influência da televisão no imaginário dos índios Terena em Campo Grande. 2000. 110 f. Dissertação (Mestrado em Comunicação) Faculdade de Comunicação, UMESP, São Bernardo do Campo, 2000.

TONON, Joseana Burguez. Recepção de telenovelas - identidade e representação da homossexualidade: Um estudo de caso da novela Mulheres Apaixonadas. 2005. 193 f. Dissertação (Mestrado em Comunicação) - Faculdade de Arquitetura, Artes e Comunicação, UNESP, Bauru, 2005.

Recebido em: 6/07/2015

Aceito em: 27/10/2015

Endereço dos Autores:

Lourdes Ana Pereira Silva <lourde_silva@hotmail.com>

Rua Isabel Schmidt, 349 - Santo Amaro

04743-030 São Paulo, SP - Brasil

Valquíria Michela John <michela@gmail.com>

Rua Uruguai, 458 - Centro

88302-202 Itajaí, SC - Brasil 